\title{
Initiation of Development of an Early Warning System to Locate "Pockets of Child Undernutrition" at District Level
}

\author{
D.M.U.A.J.K. Dassanayake and D.G.N.G. Wijesinghe ${ }^{1^{*}}$ \\ Postgraduate Institute of Agriculture \\ University of Peradeniya \\ Sri Lanka
}

\begin{abstract}
Importance of an early warning system capable of detecting most needy populations beforehand is emphasized in preparation for effective response, particularly for a developing country like Sri Lanka where most nutrition interventions are established and maintained with limited resources. Therefore, the objective of the current study was to develop an Early Warning System to identify early "pockets of child undernutrition" by Medical Officer of Health/Deputy Director of Health Services (MOH/DDHS) divisions in Kandy District. Prevalence of underweight among children aged 1-5 years was the indicator used. MOH/DDHS areas where child underweight prevalence was continuous at least for eight quarters exceeding 30\% were classified as "pockets of child undernutrition". Predicted under 5 year old child underweight prevalence (determined using secondary data collected from year 2003 to 2006) from first quarter of 2007 to third quarter of 2009 in Kandy District, were cross-validated with real time data. Using the same trend analysis model, child underweight status for fourth quarter of 2009 and first quarter of 2010 in Kandy District (MOH/DDHS area wise) were predicted and mapped using Arc View (version 3.2) software. Predictions were significantly validated with real time data $(p<0.05)$. As per the developed early warning system, Hasalaka and Medadumbara MOH/DDHS areas were the real "pockets" that should be mostly targeted in future interventions. Further, possibilities to improve and enhance the quality of suggested early warning system were also investigated.
\end{abstract}

Keywords: Child undernutrition, early warning system, predictions.

\section{INTRODUCTION}

Sri Lanka has remarkable health statistics for a developing country with a per capita income of just US\$ 3730 (Ministry of Healthcare and Nutrition, 2006). However, despite many achievements reported in many demographic characteristics, Sri Lanka's child undernutrition rate is the highest among the countries with similar per capita income. Thus, child undernutrition has been identified as a chronic, serious and a major public health issue for decades in post independent Sri Lanka (Department of Census and Statistics, 2008).

According to Demographic and Health Survey (2006/07), 17\% of children under five years of age have been born as low birth weight babies and $21.6 \%$ of children below five years suffer from underweight (low weight-for-age), 15\% from wasting (low weight-for-height)

To whom correspondence should be addressed: wijeng@yahoo.com

Department of Food Science and Technology, Faculty of Agriculture, University of Peradeniya, Peradeniya

Sri Lanka 
and $18 \%$ from stunting (low height-for-age). Therefore, in Sri Lanka, one out of three pre school aged children is malnourished.

Sri Lanka being a developing country, nutrition and health interventions are established and maintained with limited resources. Direction of limited resources at a large, low-risk population is therefore a waste and consequently many cost effective opportunities to address the real problem may have been missed. Thus, absence of a spatially targeted Early Warning System that is capable of detecting most needy children beforehand, which will allow more timely, targeted and relevant responses could be considered as a major structural weakness in the healthcare delivery system of Sri Lanka.

Within this background the present study was carried out with the following objectives.

(i) To cross validate previously predicted (Dassanayake and Mahawithanage, 2007) child undernutrition prevalence (indicator: underweight prevalence [\%] among under five year olds) by Medical Officer of Health/Deputy Director of Health Services (MOH/DDHS) divisions in Kandy District from first quarter of 2007 to third quarter of 2009 with real time data.

(ii) To develop a spatially targeted Early Warning System to detect "pockets of child undernutrition" (indicator: underweight prevalence [\%] among under five year olds) by $\mathrm{MOH} / \mathrm{DDHS}$ divisions in Kandy District.

\section{METHODOLOGY}

This study was done as a continuation of the study "Application of Geographical Information Systems (GIS) for Spatially Targeted Interventions to Combat Child Malnutrition at District Level" (Dassanayake and Mahawithanage, 2007).

\section{Overview of the previous study}

The study was carried out in Kandy District of Central Province where there are 21 $\mathrm{MOH} / \mathrm{DDHS}$ divisions. The area is composed of urban, rural and estate sectors comprising a total (reported) under five year old population of 420,016 at the end of July 2007 (Central Province Provincial Director of Health Services [PDHS] office, Kandy).

Proxy indicator used was the percentage of children (aged 1-5 years) who weighed below the third percentile of weight-for-age growth curve. This was derived for all the $21 \mathrm{MOH} / \mathrm{DDHS}$ areas in Kandy District from first quarter, 2003 to fourth quarter, 2006 using the following equation (WHO Global Database on Child Growth and Malnutrition, 1997).

Percentage of child weights below the third percentile for the $\mathrm{y}^{\text {th }}$ quarter of year $\mathrm{x}$

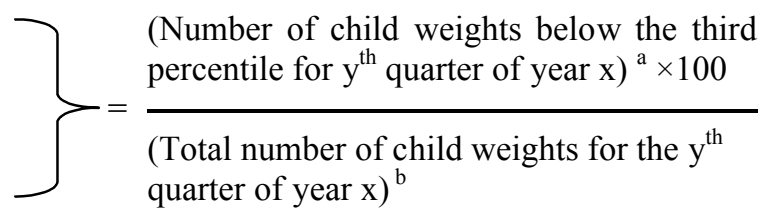

Superscripts ' $a$ ' and ' $b$ ' were obtained from quarterly review of monthly return summary sheets (also known as 509 sheets) of each quarter available at Central Province PDHS office, Kandy. 
Linear trend models were developed using the available secondary data (from first quarter, 2003 to fourth quarter, 2006) to predict under five year old child underweight prevalence in Kandy District (MOH/DDHS area wise) from the first quarter, 2007 to the third quarter, 2009 using Minitab (version 14.0) software (National Institute of Standards and Technology, Inc; PA, USA). These predicted values (from first quarter, 2007 to third quarter, 2009) in the previous study were cross validated and used for the initiation of development of the early warning system in the present study.

\section{Cross validation of predictions}

The predicted under five year old child underweight prevalence values obtained in the previous study were cross validated with real time data using bivariate correlation method with the help of Minitab (version 14.0) software. Separate validations were done temporally (for the 11 quarters from the first quarter, 2007 to the third quarter, 2009) and spatially (for the $21 \mathrm{MOH} / \mathrm{DDHS}$ areas in the Kandy District).

\section{Classification of risk areas}

Based on WHO underweight prevalence cut off values (WHO Global Database on Child Growth and Malnutrition, 1997) the MOH/DDHS areas were classified into four categories as low-risk, moderate-risk, high-risk or very high-risk areas if the underweight prevalence was $<10 \%, 10-19 \%, 20-29 \%$ and $>30 \%$, respectively. The areas where child underweight prevalence was continuous at least for eight quarters exceeding $30 \%$ were identified as "pockets of child undernutrition".

\section{Development of spatially targeted early warning system}

Using the same trend analysis model, child underweight prevalence for the fourth quarter, 2009 and the first quarter, 2010 in Kandy District (MOH/DDHS area wise) were predicted.

The base map of Kandy District (MOH/DDHS area wise), which was collected from Kandy District Survey Department was digitized and the predicted child underweight prevalence values, were mapped using Arc View (version 3.2) software (Environmental Systems Research Institute, Redlands, CA). The colour code used for mapping was the "traffic light colour system" (International Strategy for Disaster Reduction, 2004) where the very highrisk areas ("pockets of child undernutrition"), high-risk areas, moderate-risk areas and lowrisk areas were represented in red, yellow, greenish yellow and dark green colours respectively. Possibilities and considerations to improve the quality of suggested early warning system were also investigated.

\section{RESULTS AND DISCUSSION}

\section{Temporal cross validation of the predictions}

In the temporal cross validation analysis, all the predicted values in the previous study, were significantly validated $(\mathrm{p}<0.05)$ with the respective real time data (Table 1$)$. 
Table 1. Temporal cross validation results of predicted under five year old child underweight prevalence (\%) from first quarter, 2007 to third quarter, 2009 in Kandy District vs. respective real time data

\begin{tabular}{lcc}
\hline Year and quarter & Correlation coefficient (r) & p value* \\
\hline 2007 First quarter & 0.841 & 0.000 \\
Second quarter & 0.902 & 0.000 \\
Third quarter & 0.960 & 0.000 \\
Fourth quarter & 0.961 & 0.000 \\
2008 First quarter & & \\
Second quarter & 0.599 & 0.003 \\
Third quarter & 0.831 & 0.000 \\
Fourth quarter & 0.884 & 0.000 \\
$2009 \quad 0.928$ & 0.000 \\
First quarter & & \\
Second quarter & 0.986 & 0.000 \\
Third quarter & 0.981 & 0.000 \\
\end{tabular}

${ }^{*} \mathrm{p}<0.05$ was considered as statistically significant

\section{Spatial cross validation of the predictions}

In the spatial cross validation analysis, the validations were not that strong as per temporal validation (Table 2). However reason/s for this observation was not investigated in the present study.

Table 2. Spatial cross validation results of predicted under five year old child underweight prevalence (\%) from first quarter, 2007 to third quarter, 2009 in Kandy District vs. respective real time data

\begin{tabular}{lcc}
\hline MOH/DDHS area & Correlation coefficient (r) & p value \\
\hline Hasalaka & -0.313 & 0.192 \\
Ududumbara & 0.570 & $0.042^{*}$ \\
Medadumbara & -0.727 & $0.005^{*}$ \\
Panvila & 0.500 & 0.082 \\
Kundasale & -0.671 & $0.012^{*}$ \\
Wattegama & -0.383 & 0.196 \\
Akurana & 0.267 & 0.378 \\
Pujapitiya & -0.387 & 0.191 \\
Galagedara & 0.712 & $0.006^{*}$ \\
Hatharaliyadda & 0.229 & 0.452 \\
Werellagama & 0.305 & 0.311 \\
Kandy Municipal Council (KMC) & 0.719 & $0.006^{*}$ \\
Yatinuwara & 0.327 & 0.276 \\
Gangawatakorale & 0.804 & $0.001^{*}$ \\
Udunuwara & -0.121 & 0.693 \\
Thalathuoya & 0.557 & $0.048^{*}$ \\
Galaha & 0.641 & $0.018^{*}$ \\
Doluwa & 0.532 & 0.061 \\
Gampola & 0.123 & 0.688 \\
Kurunduwatta & 0.758 & $0.003^{*}$ \\
Nawalapitiya & -0.231 & 0.447 \\
Kandy District (total) & 0.131 & 0.670 \\
\hline
\end{tabular}

* Statistically significant $(\mathrm{p}<0.05)$ 
If the real prevalence trend line was lower (better) than the respective predicted prevalence trend line, the sign on $r$ value is negative (-) and vise versa. As such, for seven MOH/DDHS areas namely, Hasalaka, Medadumbara, Kundasale, Wattegama, Pujapitiya, Udunuwara and Nawalapitiya the real time picture was better than the predicted situation (Table 2).

When raw data are considered, following data inconsistencies were observed in the current study:

Before year 2007, total under 5 year old population was considered as one category, whereas after year 2007, 1-2 year olds and 2-5 year olds are considered as two separate categories.

Before year 2007, there were only $21 \mathrm{MOH} / \mathrm{DDHS}$ areas in Kandy District and from year 2007 onwards, there are $23 \mathrm{MOH} / \mathrm{DDHS}$ areas in the District. Bambaradeniya and Menikhinna areas which were previously a part of Kundasale MOH/DDHS area are now considered as two separate MOH/DDHS areas.

However, the above data inconsistencies would not have a significant impact on the results as the total under five year old population was the concern.

\section{Prediction of child underweight prevalence for the next two quarters and development of early warning system}

As predictions of the previous study were well validated with real time data $(\mathrm{p}<0.05)$, the same model was used to predict the child undernutrition prevalence in Kandy District for the fourth quarter, 2009 and the first quarter, 2010. Since trend analysis is time sensitive (International Strategy for Disaster Reduction, 2004), predictions were done only for the next two immediate quarters using real time secondary data. To monitor the trend lines more accurately data from the previous study were also included.

As per the prediction, approximately $29 \%$ and $33 \%$ of the MOH/DDHS areas in Kandy District will be at very high-risk ("pockets of child undernutrition") during the fourth quarter, 2009 and the first quarter, 2010, respectively (Table 3).

Table 3. Predicted risk status of estimated under five year old child underweight prevalence (\%) of Kandy District for the fourth quarter, 2009 and the first quarter, 2010

\begin{tabular}{|c|c|c|c|c|}
\hline \multirow[t]{3}{*}{ Risk category* } & \multicolumn{4}{|c|}{ Year and quarter } \\
\hline & \multicolumn{2}{|c|}{$4^{\text {th }}$ quarter, 2009} & \multicolumn{2}{|c|}{$1^{\text {st }}$ quarter, 2010} \\
\hline & $\mathbf{n} * *$ & $\%$ & $\mathrm{n}$ & $\%$ \\
\hline Low-risk & 0 & 0 & 0 & 0 \\
\hline Moderate-risk & 3 & 14.3 & 2 & 9.5 \\
\hline High-risk & 12 & 57.1 & 12 & 57.1 \\
\hline $\begin{array}{l}\text { Very high-risk ("pockets of child } \\
\text { undernutrition") }\end{array}$ & 6 & 28.6 & 7 & 33.4 \\
\hline Total & 21 & 100 & 21 & 100 \\
\hline
\end{tabular}

*Classification is based on WHO Global Database on Child Growth and Malnutrition (1997)

**Number of MOH/DDHS areas

Figures 1 and 2 outline the MOH/DDHS area-wise spatial distribution of predicted under five year old child underweight prevalence (\%) in Kandy District for the fourth quarter, 2009 and the first quarter 2010, respectively. 
These thematic representations could be used as an early warning system to locate precise "pockets of child undernutrition" in the District beforehand.

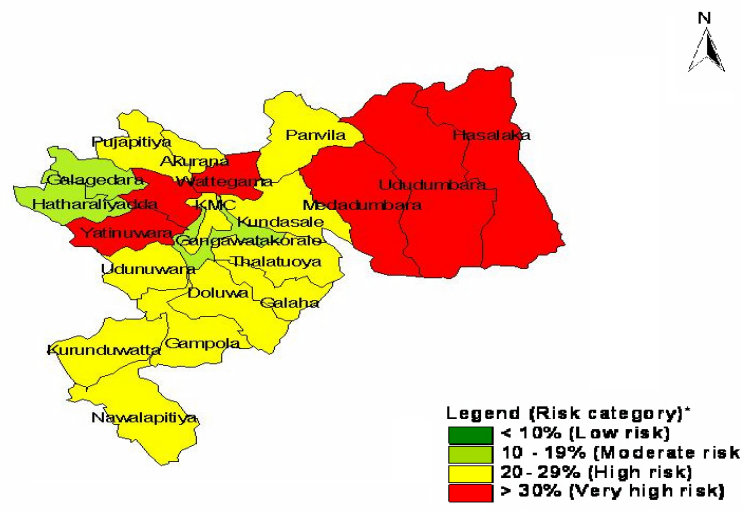

Fig. 1. Predicted spatial variation of estimated under five year old child underweight prevalence (\%) in Kandy District for the fourth quarter, 2009 (*Classification is based on WHO Global Database on Child Growth and Malnutrition, 1997)

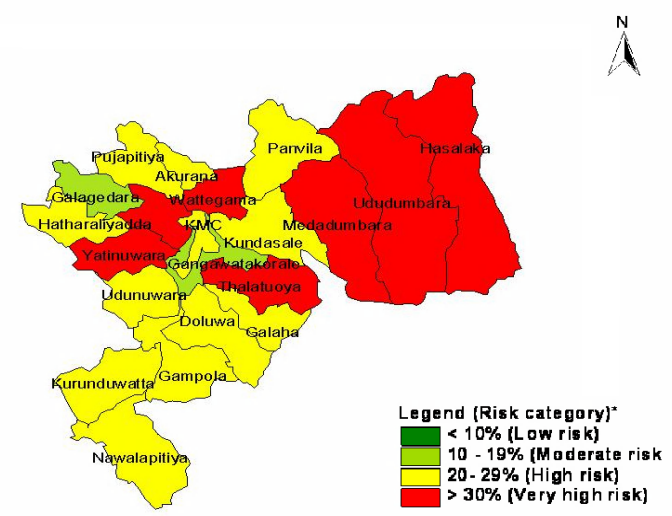

Fig. 2. Predicted spatial variation of estimated under five year old child underweight prevalence (\%) in Kandy District for the first quarter, $2010(*$ Classification is based on WHO Global Database on Child Growth and Malnutrition, 1997)

As per the developed early warning system, Hasalaka, Ududumbara, Medadumbara, Wattegama, Werellagama and Yatinuwara MOH/DDHS areas were the "pockets of child undernutrition" in Kandy District in the third quarter, 2009 (Fig. 1) whereas in the first quarter, 2010, Thalatuoya MOH/DDHS area was also be added to this category, in addition to previously mentioned six areas (Fig. 2).

According to the classification criterion used (WHO Global Database on Child Growth and Malnutrition, 1997), all the areas where child underweight prevalence is greater than $30 \%$ are categorized as very high-risk areas. However, this classification criterion is unable to distinguish an extremely high-risk area where prevalence rate could be even greater than $50 \%$ from an area that is just above $30 \%$ as both the areas are categorized under one group (i.e. very high-risk area). This is one of the major limitations of the WHO underweight prevalence cutoff classification criterion. Further, the false positives, that are not really at high risk category, but are predicted to be as high risk areas in thematic maps may mislead 
the decision makers in resource allocation. In particular, the values that lie closer to borderlines/cutoffs are the values that are more prone to be false positives.

To minimize these possible errors and to have a clear picture of the real situation, a slightly modified classification is proposed in which the prevalence cutoff values determining the high-risk levels (i.e. $>30 \%$ category) are altered (Figures 3 and 4).

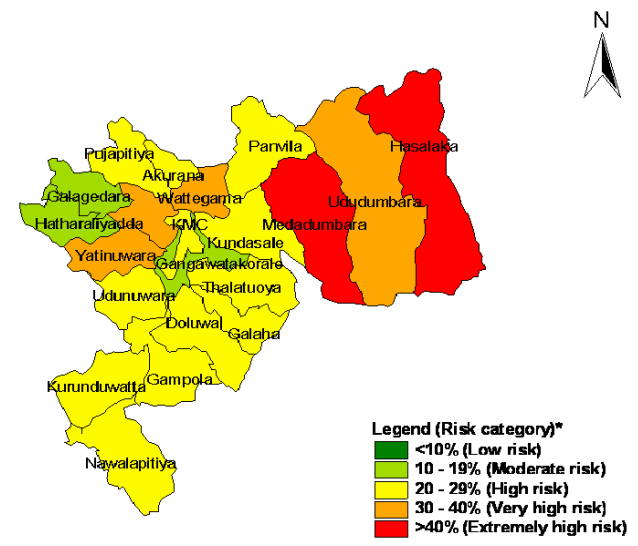

Fig. 3. Predicted spatial variation of estimated under five year old child underweight prevalence (\%) in Kandy District for the fourth quarter, 2009 (*Classification is based on the proposed modified classification)

In the proposed modified classification, areas which previously were very high-risk areas (underweight prevalence $>30 \%$ ) are subdivided into two categories as very high-risk areas (where underweight prevalence is 30-40\%) and extremely high-risk areas (underweight prevalence $>40 \%$ ). According to the new classification, extremely high-risk areas are Hasalaka and Medadumbara MOH/DDHS areas, which are the real "pockets of child undernutrition" out of previously detected seven areas. Figures 3 and 4 represent the real "pockets of child undernutrition" in Kandy District for the third quarter, 2009 and the first quarter, 2010, respectively.

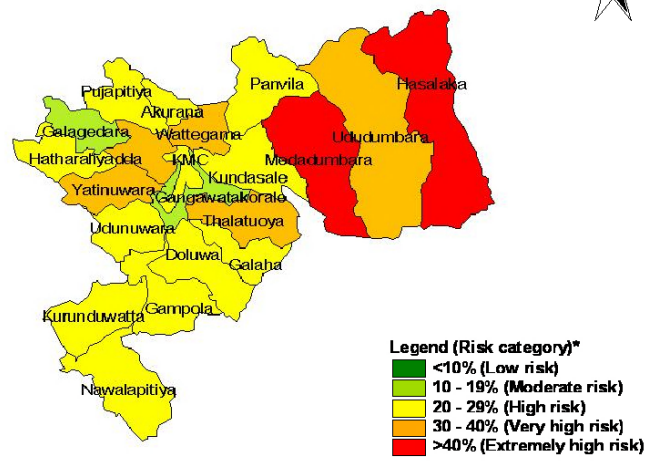

Fig. 4. Predicted spatial variation of estimated under five year old child underweight prevalence (\%) in Kandy District for the first quarter, $2010(*$ Classification is based on the proposed modified classification) 
When Kandy District is considered as one unit, at the baseline (i.e. first quarter, 2003) it was a high-risk area (overall child underweight prevalence was $21 \%$ ) whereas in third quarter, 2009 it was a "pocket of child undernutrition" or a very-high risk area (estimated overall child underweight prevalence was 30\%). Therefore, 9\% rise in overall District child underweight prevalence was observed during the study period (Fig. 5). This rapid rise in child undernutrition rate in Kandy District within just six years is an alarming condition and it indicates the need for an immediate solution and again emphasizes the importance of having spatially targeted interventions over blanket interventions.

However, this observation could not be compared with the national statistics which indicated a reduction of Sri Lankan under five year old underweight prevalence from $29.8 \%$ in year 2000 to $21.6 \%$ in year 2007 (Department of Census and Statistics, 2008) (Fig. 5) because of the differences in cutoffs being used, variation of population densities, etc.

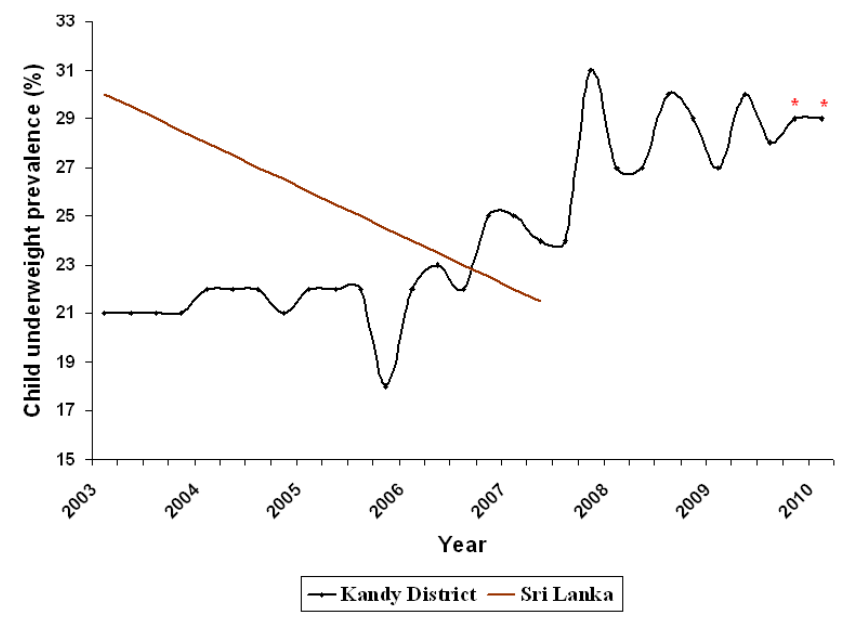

Fig. 5. Temporal variation of overall child underweight prevalence (\%) in Kandy District from first quarter, 2003 to first quarter, 2010 (values for fourth quarter, 2009 and first quarter, 2010 which are highlighted by two asterisks are predictions) and change of child underweight prevalence (\%) in Sri Lanka over time (Department of Census and Statistics, 2008)

Another noteworthy observation of the study was, though the estimated District prevalence in the third quarter, 2009 is $30 \%$, it varies within a wide range within the District itself. For instance in some MOH/DDHS areas it was around 53\%, dragging down the overall District average (e.g. Medadumbara MOH/DDHS area) while in some areas it was only around 6\% (e.g. Galagedara MOH/DDHS area). Thus, huge disparities exist among the underweight prevalence rates within the District. Therefore, District level is not a good scale or a boundary for decision making and resource allocation, because the huge disparities among various community blocks are hidden when a District is considered as one unit. Therefore, the most suitable demarcation boundary to assess and address such a problem is the lowest administration boundary of a country. Therefore, more focus at the lowest possible demarcation boundary in the country, in terms of problem analysis and resource allocation at sub National levels, is encouraged.

When risk is considered, if risk is higher for a particular subpopulation because of abnormal exposure (e.g. seasonal food shortage, poverty) rather than susceptibility, there is a potential 
to consider strategies to reduce further exposure of that subgroup. If an identifiable subpopulation is more susceptible due to inherent genetic or other related factors, more serious interventions are required, which might not be possible at this stage. Therefore, assessment of reason/s for higher risk (i.e. abnormal exposure or more susceptibility), which was not investigated in the current study, would be potential concerns for future studies.

Monitoring trends in health and nutrition related events are an important public health function and ability to predict future status makes prevention a more realistic prospect. Thus, the suggested model could be used as a potential tool for both initiating and evaluating specific nutrition interventions. Further, successful risk reduction and mitigation measures are always multi-sectoral and inter-disciplinary in nature. They require knowledge, information, capacities and many inputs of wide range of sectors and organizations. Moreover, since preventive measures will take time to impact significantly on improving child nutritional status, they will be required to be continued for many years to come.

\section{CONCLUSIONS}

As per the developed early warning system, Hasalaka, Ududumbara, Medadumbara, Wattegama, Werellagama, Yatinuwara and Thalathuoya MOH/DDHS areas are the predicted "pockets of child undernutrition" in Kandy District for the third quarter, 2009 and the first quarter, 2010 when WHO classification criterion is used. However, according to the proposed, modified classification, Hasalaka and Medadumbara MOH/DDHS areas are the real "pockets of child undernutrition" in Kandy District. Therefore, these areas should be given the priority and be mostly targeted in future nutritional interventions.

\section{REFERENCES}

Dassanayake, D.M.U.A.J.K. and Mahawithanage, S.T.C. (2007). Development of GIS aided resource management system for spatially targeted interventions at district level, Proceedings of the Fourth National Symposium on Geo-Informatics. pp. 85-93. In: De Silva. R.P. (Ed.) Geo-Informatics Society of Sri Lanka and University of Peradeniya, Sri Lanka [online]. [Accessed on 01.06.2010]. Available at http://www.gissl.lk/fourth-symposium/9-sym-webpapers/pdf

Department of Census and Statistics (2000). Sri Lanka Health and Demographic Survey 2000. Department of Census and Statistics, Colombo, Sri Lanka.

Department of Census and Statistics (2008). Sri Lanka Health and Demographic Survey 2006/07. Department of Census and Statistics, Colombo, Sri Lanka.

International Strategy for Disaster Reduction (2004). Local Governments and Disaster Risk Reduction: Good Practices and Lessons Learned. International Strategy for Disaster Reduction, Chatelaine, Geneva [online]. [Accessed on 01.06.2010]. Available at http://www.preventionweb.net/english/professional/publications/v.php

Ministry of Healthcare and Nutrition (2006). Annual Health Bulletin. Ministry of Healthcare and Nutrition, Colombo, Sri Lanka.

WHO (1997). Global Database on Child Growth and Malnutrition. Doc/WHO/NUT/97.4. World Health Organization, Geneva, Switzerland. 